\title{
Evaluation of the effects of coal grinding in terms of coal water slurry preparation
}

\author{
Jolanta Robak ${ }^{1, a}$, Karina Ignasiak ${ }^{1}$, and Michał Rejdak ${ }^{1}$ \\ ${ }^{1}$ Institute for Chemical Processing of Coal, 41-803 Zabrze, Zamkowa 1 St.
}

\begin{abstract}
Coal Water Slurry (CWS) is a specific form of solid fuel. It occurs in the form of finely ground coal particles and water. Depending on the use, the content of combustible matter is from 40 to $70 \%$ by weight. The attractiveness of the fuel is primarily its properties, i.e. liquid form, high energy efficiency (for water evaporation 4\% energy is used - for CSW with $70 \%$ concentration of coal), decreased environmental impurities (lower NOx emission) and reduced risk of explosion. The advantages of CWS fuels, the possibility of independence from petrochemical fuels, wide availability of coal and emphasis on the use of cleaner technologies are the driving force for development of slurry fuel technologies. The major parameters characterizing the fuel suspension are: solid phase concentration (share of coal in the slurry expressed as either weight or volume fraction of dry coal), time stability (resistance to delamination and separation of the dispersed phase from the continuous phase) and viscosity, determining the flow of suspension. The mentioned parameters are dependent on the susceptibility of coal for production of aqueous suspensions (slurrability), conditioned by natural properties of coal, such as: coalification degree, petrographic composition and surface properties. They are also dependent on the slurry fuel preparation process: particle size, solid phase concentration, used additives (stabilizing and dispersion agents) and modification of primary coal properties (ash removal, change of surface properties). Preparation of sustainable, high concentrated CWS fuel coal is promoted by the hydrophobic nature of the coal surface, characteristic for coals of higher coalification. A great technological problem is to obtain a highly concentrated coal slurry fuel from less coalified hydrophilic steam coals. The paper presents the results of lab scale research on the CWS prepared from Polish steam coal by wet grinding in mill drum and vibrating. The milling process was carried out in a batch system by varying the composition of the grinding media and varying degrees of working space filling. The feed was pre-ground steam coal mixed with water at the ratio of 1: 1 . The changes of particle size, viscosity and stability of suspensions in time were assessed. The milling effectiveness was higher for the vibrating mill. After the same milling time the quality of the obtained product was higher. The obtained milling degree was depended on the share and composition of grinding aids. In the investigated range (10-30\% share mill working space), the use of higher share of grinding aids caused higher milling degree of coal. A trend was observed that stronger fragmentation of coal was achieved with the use of polydisperse composition of aids distinguished by smaller diameters. The changes of granulation influenced the viscosity and stability of the obtained product. The lower the mean particle size, the higher the viscosity and stability of the obtained product was particularly noted for the vibrating mill.
\end{abstract}

\footnotetext{
${ }^{\text {a }}$ Corresponding author: office@ichpw.pl
} 